\title{
Emniyet Kilidi Üretim Hattının Simülasyon Kullanılarak İncelenmesi
}

\author{
Büşra Bakdaal ${ }^{1 *}$, Esra Kurt Tekez ${ }^{2}$ \\ ${ }^{1 *}$ Sakarya Üniversitesi, Fen Bilimleri Enstitüsü, Endüstri Mühendisliği Bölümü, Sakarya, Türkiye, (ORCID: 0000-0002-3936-2928), \\ busra.bakdaal@ogr.sakarya.edu.tr \\ ${ }^{2}$ Sakarya Üniversitesi, Mühendislik Fakültesi, Endüstri Mühendisliği Bölümü, Sakarya, Türkiye (ORCID: 0000-0002-0429-5593), etekez@sakarya.edu.tr
}

(1st International Conference on Applied Engineering and Natural Sciences ICAENS 2021, November 1-3, 2021)

(DOI: 10.31590/ejosat.1014411)

\begin{abstract}
ATIF/REFERENCE: Bakdaal, B. \& Kurt Tekez, E. (2021). Emniyet Kilidi Üretim Hattının Simülasyon Kullanılarak İncelenmesi. Avrupa Bilim ve Teknoloji Dergisi, (28), 1258-1264.
\end{abstract}

\section{$\ddot{O} z$}

Büyük ölçekli şirketlerde olduğu gibi, bu şirketlere fason üretim yapan orta ve küçük ölçekli işletmelerde de iş süreçleri yönetimi son derece önemlidir. Bu işletmelerin günümüzde varlıklarını sürdürebilmeleri ve rekabet avantajını sağlayabilmeleri için üretim süreçlerini gözden geçirerek, çıktıyı arttıracak çalışmalar yürütebilmesi ve bunun sonucunda ürün teslim sürelerini daha kısa sürede gerçekleştirebilmeleri gerekmektedir. İmalat çevrim süresinin kısaltılması, fason üreticilerin pazar paylarında ve üretim kapasitelerinde artışa imkan sağlayacaktır. Bu avantajları elde edebilmek için, mevcut üretim sistemlerini detaylı bir şekilde analiz etmeleri ve sistemi iyi yönetebilmeleri gerekmektedir. Bu çalışmada, emniyet ve güvenlik sistemleri sektörüne fason imalat yapan bir firmada, emniyet kilidi üretim ve montaj süreçlerinde ortaya çıkan aksaklıklar ve gecikmeler tespit edilmeye çalışılmıştır. Sürecin, hammaddenin sisteme girişi ve nihai ürün olarak çıkışına kadar simülasyonu oluşturulmuş ve tüm istasyonların sistemin çıktısına olan etkisi incelenmiş, darboğazlar tespit edilmiştir. Çalışmanın sonucunda sistem üzerinde yapılan bazı değişiklikler ile çıktı miktarının artarak gecikmelerin azalabileceği sonucuna varılmıştır.

Anahtar Kelimeler: Simülasyon, Üretim Sistemi, Rekabet Gücü

\section{Examination of Safety Lock Production Line Using Simulation}

\begin{abstract}
As in large-scale companies, business process management is extremely important in medium and small-scale enterprises that outsource to these companies. In order for these enterprises to maintain their existence and provide competitive advantage today, they need to examine their production processes, carry out actions to increase output and, as a result, realize product delivery times in a shorter time. Reducing the manufacturing cycle time will allow for an increase in the market shares and production capacities of contract manufacturers. In order to obtain these advantages, they need to analyze the existing production systems in detail and manage the system well. In this study, it has been tried to determine the faults and delays that occur in the production and assembly processes of the safety lock in a company that makes contract manufacturing for the safety and security systems sector. The process was simulated from entering the raw material to exiting as the final product, and the effect of all stations on the output of the system was examined, and bottlenecks were identified. As a result of the study, it was concluded that with some changes made on the system, the amount of output can be increased and the delays can be reduced.
\end{abstract}

Keywords: Simulation, Production System, Competitiveness

\footnotetext{
*Sorumlu Yazar: busra.bakdaal@,ogr.sakarya.edu.tr
} 


\section{Giriş}

Son yıllarda üretim sistemlerinin davranışlarının ve performansının değerlendirilmesi önem arz etmektedir. Üretimle ilgili karar destek sistemlerinden biri olan simülasyon, hem üretim sistemlerinin yapısında hem de performans analizinde kullanılan etkili bir araçtır. Bir üretim sisteminin modelini oluşturmak özel yetkinlik gerektiren zor bir iştir [1]. Bu süreci hılandırmak ve kolaylaştırmak için geliştirilen simülasyon yazılımları mevcutttur. Simülasyon yapılacak konuya göre kullanım ve yazılım dilleri farklılık gösterebilmektedir. Örneğin üretim sektörüne yönelik kullanılan programlar olabileceği gibi, genel amaçlı olarak kullanılacak simülasyon modelleme dilleri de olabilmektedir.

Halihazırda çalışmakta olan gerçek bir sistem üzerinde değişiklik yapmak bazı durumlarda olası değildir. Bir diğer durum ise sisteme uygun olmayan sonuçlar doğurarak müdaheleye sebep olabilir. $\mathrm{Bu}$ nedenle mevcut sistemin kurgulanarak simüle edilmesi süreç iyileştirmesine ya da herhangi bir proseste meydana gelecek değişikliğin etkisini gözlemlemeye yardım eder. $\mathrm{Bu}$ durum geri dönüşü olmayacak işlemlerin doğmasını engelleyerek, olası çözümler üretilmesine olanak sağlar. Olası çözüm ve etkilerin tespitinde gerçek sistemin iyi analiz edilmesi gerekmektedir.

Literatürde üretim sektöründe karşılaşılan sorunları çözmeye yönelik simülasyon tekniğinden faydalanan çalışmalar aşağıdaki gibi özetlenmiştir.

Popovics ve diğerleri [1], üretim sistemlerinin simülasyonu için benzetim modelinin genel veri yapısı üzerine yazılımlar geliştirmişler ve bu yazılımları doğrulamak için farklı çalışmalar yürütmüşlerdir. Sistemin detaylarının ve toleranslarının ne kadar iyi tanımlanırsa o kadar doğru sonuçlar elde edilebileceğini savunmuşlardır. Ünal ve Bilget [2] çalışmalarında, bir konfeksiyon firmasında üç farklı ürünün üretim süreçlerini inceleyerek çevrim sürelerini belirlemiş ve simülasyon tekniği ile model oluşturmuşlardır. Daha sonra yalın üretim prensiplerine göre yeniden bir sistem tasarlayarak SIMUL8 yazılımıyla alternatif modeller oluşturmuşlar, bu alternatifler ile hat dengelemesine izin veren, "kalp algoritması" ile tüm modelleri test etmişlerdir. $\mathrm{Bu}$ algoritmanın kurallarına göre oluşturulan modelde operatör başına ortalama verim \%6,99 arttırılmış, ana modeller üzerinde iş akışlarında yaptıkları değişiklikler ile tüm modellerde \%20'ye varan iyileştirmeler elde etmişlerdir. Neeraj ve diğerleri [3], bir firmada üretim biriminin akışını incelemek ve darboğazları bulmak ve aynı zamanda verimliliği ve işgücü gereksinimlerini hesaplamak amacıyla Arena yazılımından yararlanmışlardır. Yeni bir model sunumu ile verimliliği \%6 oranında arttırmış ve işgücü gereksinimlerini \%8,33 oranında azaltmışlardır. Bunların yanısıra simülasyonun fabrika yerleşimlerini tasarlamak ve düzenlemek için de kulanılabilir olduğunu savunmuşlardır. Bir başka çalışmada, Kocaköz [4] simülasyon yönteminden faydalanarak, bitirme projesinde LPG silindir imalat hatlarının düzenlenmesini sağlamıştır. Bazı kaynakların kapasitesini arttırarak günlük üretim miktarında \%56 artış sağlamıştır. Yine talaşı imalat yapan bir firmada Arslankaya ve Duran [5], Jeneratör üretimini ProModel paket programını kullanarak simüle etmiş, bu çalışmayla birlikte iş istasyonları arasında iş gücü ve kaynak kullanımını dengelemeyi ve üretimi satndartlaştırarak maliyetleri azaltmayı amaçlamışlardır. Yapılan uygulama çalışmasıyla birlikte üretimdeki tezgah sayılarını azaltılması ve robot alımı ile \%21 iyileşme sağlamışlardır. Sütçü ve diğerleri [6], bir mobilya üretim tesisinin, iş ve zaman etüdü e-ISSN: 2148-2683 analizinde REFA formlarını kullanarak veri toplamışlardır. $\mathrm{Bu}$ verileri Arena 14.0 benzetim yazılımı üzerinde modellemişlerdir. Darboğaza neden olan iş istasyonlarında iş zenginleştirme, iş basitleştirme ve iş değişimi ile yeniden modelleme yapılmış bu sayede katma değer oluşturmayan faaliyetlerin ortadan kaldırılması ve süreç içi stokların azaltılması sağlanmıştır. Çalışma sonucunda, üretim verimliliğinde \%10'luk artışla çevrim zamanında $34 \mathrm{dk}$ kazanç elde etmişlerdir. Sakcalı ve diğerleri [7], bir mermer ocağında, simülasyon tekniğinden faydalanarak performans analizi yapmışlardır. Çalışmalarında Rockwell-Arena yazılımını kullanarak, ayrık-olay modeli kurmuş ve mevcut durum analizini gerçekleştirmişlerdir. Daha sorasında elde edilen sistem de duyarlılık analizi yapılarak kaynakların performans göstergeleri değerlendirilmiştir. Yelkenci ve Tunalı [8], 1sıtma ürünleri üretimi yapan bir işletmenin eşanjör üretim hattında modelleme çalışması gerçekleştirmişler, bu çalışma ile sistemdeki darboğazları tespit ederek istasyonların kapasitelerini iyileştirmeye yönelik alternatif modeller sunmuşlardır. $\mathrm{Bu}$ alternatifler üzerine \%95 güven düzeyinde istatistiksel analizler yapılarak, mevcut sistemde darboğaz istasyonlarından biri olan presleme istasyonuna pres makinesi yatırımı yapılmasına karar vermişlerdir. Krishnan ve diğerleri [9], bir lastik üretim şirketinde katma değersiz işleri ortadan kaldırmak, darboğazları tespit etmek ve verimlilik artışı sağlamak amaçlı mevcut proseslerin simülasyonunu gerçekleştirmişlerdir. Pareto analizi ile darboğazları belirleyerek, sorunların kök nedenlerini balık kılıçığı diyagramı kullanarak incelemişlerdir. Çözüm olarak işlem sürelerinin azaltılmasını ve makine yatırımı yapılmasını önermişlerdir. Yatırım maliyeti analizi ile başabaş süresini 88 gün olarak hesaplamışlardır.

Bilimsel araştırmalarda, benzetim metodu kullanılarak, üretim sistemleri üzerine yapılan bu çalışmalar literatüre katkı sağlamışlardır. $\mathrm{Bu}$ çalışmalar ile firmaların hali hazırda kullandıkları sistemleri simüle edebilmelerinin yatırım maliyetleri, kapasite kullanımları, varlık maliyetleri, üretim çıktı sayısı gibi bir çok konuda onlara fayda sağladığ gösterilebilmiştir.

Bu çalışmanın amacı büyük ölçekli kurumsal firmalara fason imalat yapan, küçük ve orta ölçekli işletmelerin de bu yöntem sayesinde sistem analizi yapabileceği ve rekabet gücünü arttırabilmelerine olanak sağladı̆̆ını göstermektir.

\section{Materyal ve Metot}

$\mathrm{Bu}$ çalışmada simülasyondan faydalanarak emniyet ve güvenlik sistemlerine fason imalat yapan fabrikanın emniyet kilidi üretim hattı incelenmiştir. Simülasyon, benzetim yöntemi ile gerçekte var olan bir sistemin bütün özelliklerini taşıyan, aynı çıktıları verebilen ve sistemin daha kolay bir şekilde anlaşılabilir olmasına imkan sağlayan sistemlerdir. Bir sistemin taklidini oluşturarak [10] süreç iyileştirme çalışmaları yapmaya olanak sağlayan ve farklı alternatifleri değerlendirmek için kullanılan bir problem çözme tekniğidir. Kullanıcının ürettiği çözümü analiz etmesini sağlar. Burada sistem optimize edilmeye çalışılır.

Günümüzde tıp, askeriye, trafik, üretim, ulaştırma v.b. gibi pek çok alanda simülasyondan yararlanılmaktadır. Simülasyon ile gerçek sistemin yapay bir ortamda işleyişini analiz etmek mümkündür. Böylelikle maliyetli ve zaman alıcı, bazen de imkansız olan denemeler yaparak sistemin tepkisi ölçülebilir. Aynı zamanda darboğaz tespiti ve analizinde kullanılan matematiksel ve analitik yöntemlere göre daha avantajlıdır. 
Günümüzde yaygın olarak kullanılan güçlü sayılabilecek benzetim yapabilen programlar mevcuttur. Bu çalışmada Arena programından faydalanılmıştır.

Programın içinde farklı işlevlere sahip modüller ile deneysel bir model oluşturulur. Bağlayıcı çizgiler ile de bu modüller arası bağlantılar sağlanır. Sürece gelen varlıkların gelişleri için olasılık dağılımlarından yararlanılır.

Modelin çalışmasıyla elde edilen raporlar, bazı istatistiksel verilerin alınmasına yardımcı olur. Ortalama çıktı sayısı, kaynakların kullanım oranları, hatalı ürün sayıları gibi veriler kullanılarak sistem analizi gerçekleştirilir.

Benzetim modeli oluşturulurken sistemin doğru ve eksiksiz tanımlanması, güvenilir sonuçlar elde etmek için çok önemlidir.

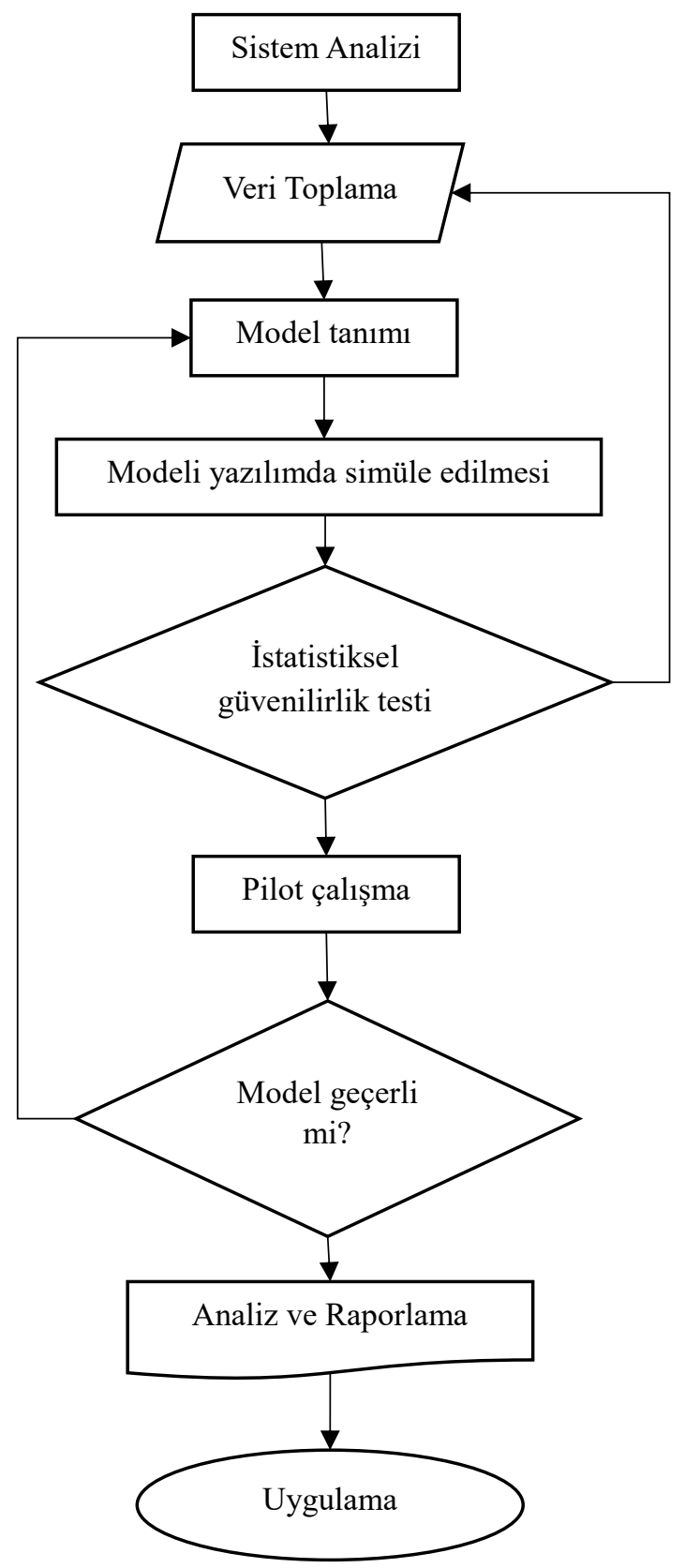

Simülasyon aşamaları şekil 1'de özetlenmiştir. Böyle bir yol izlemek sistemin gerçek gerekliliklerinin ortaya çıkmasına yardımcı olacaktır. Böylece ihtiyaçlara yönelik uygunluk sağlanacaktır.

Bir simülasyon çalışması sistemin analizi ile başlar. Sistemde oluşan probleme ve amaca yönelik veri toplanır. Daha sonra bu veriler 1şı̆̆ında model kurulur ve bu model yazılım ortamında simüle edilir. Kurulan model istatistiksel güvenilirlik testlerine tabii tutularak verilerin doğruluğu kontrol edilir. Bu kontrol, modelin geçerliliği açısından önemlidir. Kurulan model çalıştırılır ve sonuçlar incelenerek doğru çalışıp çalışmadığı kontrol edilir. Eğer sonuçlar gerçekliği yansıtmıyorsa elde edilen veriler gözden geçirilerek model baştan kurulur. Son olarak çalışma sonrası elde edilen çıktılar analiz edilerek raporlanır.

\section{Araştırma Sonuçları ve Tartışma}

Uygulamanın yapıldığı firmanın faaliyet konusu; emniyet ve güvenlik sistemlerine fason imalat yapmaktır. Firma aynı zamanda enjeksiyon makinelerinde kullanılan kalıpların imalatı, tadilatı ve bakımları ile ilgilenmektedir. İş süreçleri, organizasyon müdürü tarafindan yönetilmektedir. İşletme günlük 8 saat, haftada 6 gün çalışmaktadır. Firma hammaddeyi yurt içinden temin etmektedir.

Sektörün önde gelen markalarına çalışan firma, pimapen kapı ve pencere aksanları üretmektedir. Yaklaşık $60 \mathrm{kalem}$ ürün çeşidi bulunan firmanın ürettiği parçalardan bazıları; barel, tüp, piston, emniyet kilidi, menteşe, ispanyolet karşılığı, göbek ve kapı koludur.

Bu çalışmada hırsız emniyet kilidi ürünü için simülasyon çalışması yapılmıştır. Şekil 2'de ürüne ve kullanım alanına ait örnek görseller verilmiştir.
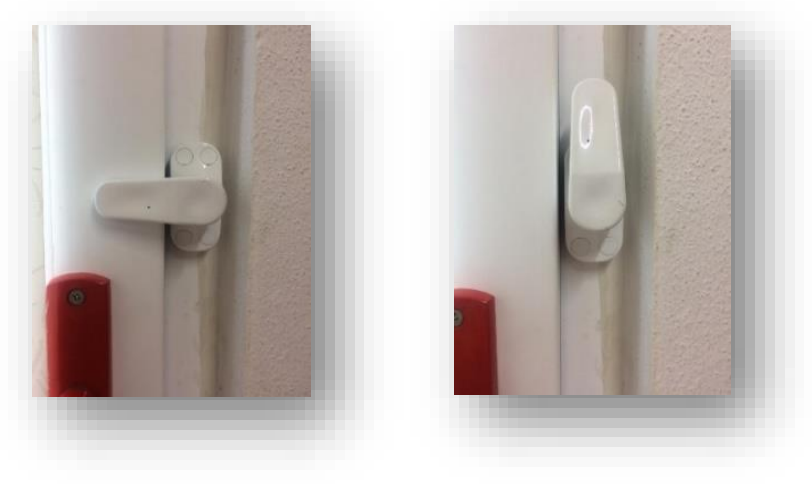

Şekil 2 Emniyet Kilidi ve Kullanım Alanı

Hammadde olarak zamak-5 kullanılmaktadır. Zamak içerisinde alüminyum, çinko ve bakır bileşenlerini bulundurmaktadır. Ayrıca alüminyuma göre daha ucuz bir hammadde olduğundan tercih edilmektedir. Hammadde alımı ile başlayan sürece ait iş akışı şekil 3'de verilmiştir:

Şekil 1 Simülasyon Aşamaları 


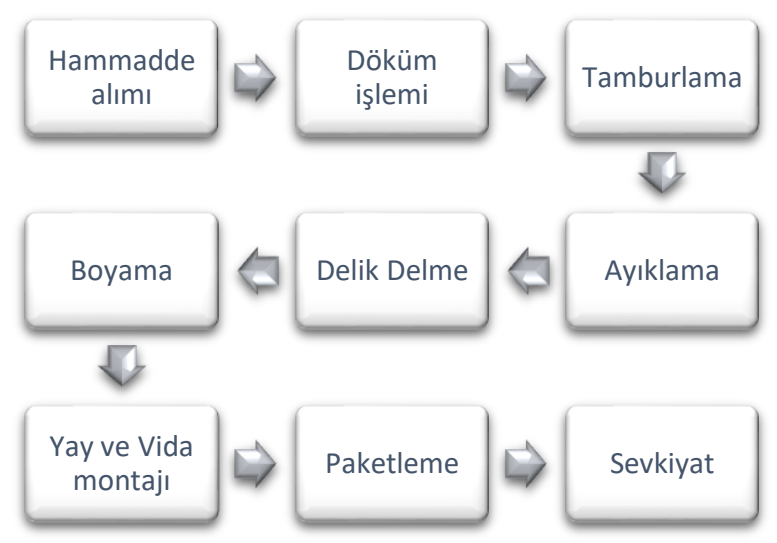

Şekil 3 Emniyet Kilidi İş Akışı

Döküm işlemi: Döküm işlemi enjeksiyon makinesi ile yapılmaktadır. $430-450{ }^{\circ} \mathrm{C}$ 'de eriyik hale gelen hammadde piston yardımıyla kalıp içerisine yüklenmekte ve basım işlemi gerçekleşmektedir. Her basımdan sonra kalıp açılmakta ve yarı mamül haline gelen hammadde kalıp içerisindeki iticilerle kalıp içerisinden çıkartılarak, kalıp yüzeyinin yine makine tarafından otomatik yağlanması işlemi gerçekleşmektedir. Aynı zamanda kalıp göz sayısının fazla olması ile her basımda 2 adet üst gövde ve 2 adet alt gövde elde edilir.

Tamburlama: Döküm işlemi gerçekleşen yarı mamüller 200 adetlik partiler halinde tambur makinesinin haznesine yüklenmekte ve burada tamburlama işlemi gerçekleşmektedir. Tamburlama işlemi, döküm sırasında oluşan yolluklardan ve hava ceplerinden kurtulmak için yapılır. Hava cepleri döküm gerçekleşmeden kalıp kapandığı zaman kalıbın içerisinde kalan havayı hapsetmek için, yolluk ise eriyik hammaddenin kalıp içerisinde ilerlemesini/yürümesini sağlamak için vardır.

Ayıklama: Tambur makinesinde bir süre işlem gören parçalar tamburun haznesinden ayıklanarak kauçuk kasalar yardımıyla delik delme prosesine gönderilmektedir.

Delik Delme: $\mathrm{Bu}$ proseste masa üstü matkaplar kullanılmaktadır. Operatör, parçaların üzerindeki vida deliklerinde döküm işleminden kaynaklanan çapakları temizlemektedir.

Boyama: Boyahanede parçalar tek tek asılarak üzerlerine elektro statik toz püskürtme yöntemi ile müşteri isteklerine bağlı olarak renk seçimiyle boyama işlemi gerçekleşmektedir.

Yay ve Vida Montajı: Boyanan mamüller üzerine alt ve üst gövdeyi birleştirmek amacıyla yay ve kapakların montajı gerçekleşmektedir.

Paketleme: Son olarak mamüller paketlenerek sevkiyata hazır hale getirilir.

Ürünün üretim sürecindeki iş akışı belirlendikten sonra, mevcut yerleşim düzeni, zaman etüdü çalışmaları yapılarak sistem analizi sağlanmıştır. Yapılan her işlem için operasyon süreleri üretim şefi önderliğinde, operatörlerin de görüşleri alınarak toplanmıştır. Operasyonların istatistiksel dağılımlarının belirlenmesi amaciyla toplanan veriler Arena programının input analyzer komutu ile değerlendirilmiştir. Tablo 1'de döküm işlemine ait işlem süreleri ve şekil 4'deki dağılım grafiği örnek olarak verilmiştir.
Tablo 1. Döküm prosesi işlem süreleri ve uygun matematiksel dağılım

\begin{tabular}{|l|l|l|}
\hline Proses & $\begin{array}{l}\text { İşlem süreleri } \\
\text { (saniye) }\end{array}$ & $\begin{array}{c}\text { Matematiksel } \\
\text { Dağılım }\end{array}$ \\
\hline Döküm & $14.10,14.30,14.25$, & GAMM $(0.288,4.45)$ \\
& $14.55,14.18,15.20$, & \\
& $15.33,14.17,14.48$, & \\
& $14.50,14.52,15.12$, & \\
& $15.14,14.48,15.10$, & \\
& $14.49,14.52,14.53$, & \\
& $15.40,15.32,14.48$, & \\
& $14.33,14.52,15.10$, & \\
& $14.56,14.40,15.50$, & \\
& $15.38,15.39,15.10$, & \\
& $14.00,14.33,14.48$, & \\
& $13.59,13.55,15.25$, & \\
& $14.49,14.56$ & \\
\hline
\end{tabular}

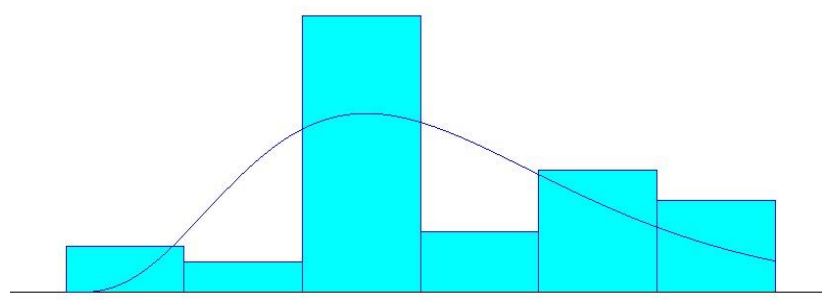

Şekil 4. Döküm Prosesine Ait Sürelerin Dağılım Grafiği

Hammadde alımı, hammaddenin azalarak tekrar istekte bulunma seviyesidir. Ortalama her 1 dakika'da bir poisson dağılımına göre sisteme hammadde girişi sağlanmaktadır. Buna göre gerçekleşen olay sayısı ortalaması Poisson dağılımına uyuyorsa, iki olayın gerçekleşmesi arasında geçen süre ortalamalı Üstel (Exponential) dağılıma uyar. Diğer prosesler için belirlenen uygun dağılımlar Tablo 2'de verilmektedir.

Tablo 2. Üretim Proseslerine Uygun Matematiksel Dağılımlar

\begin{tabular}{ccc}
\hline Proses & $\begin{array}{c}\text { Dağılım } \\
\text { Türü }\end{array}$ & $\begin{array}{c}\text { Matematiksel İfade } \\
\text { (saniye) }\end{array}$ \\
\hline Döküm & GAMMA & $13.4+$ GAMM $(0.288,4.45)$ \\
\hline Tamburlama & - & 360 \\
\hline Ayıklama & - & 320 \\
\hline Delik delme & BETA & $4.5+13 *$ BETA $(1.17,1.21)$ \\
\hline Boyama & - & 120 \\
\hline Montaj & ERLANG & $25.5+$ ERLA $(14.6,2)$ \\
\hline Paketleme & BETA & $11.5+37 * B E T A(1.19,1.54)$ \\
\hline Kutulama & TRİGULAR & TRIA $(209,210,213)$ \\
\hline
\end{tabular}



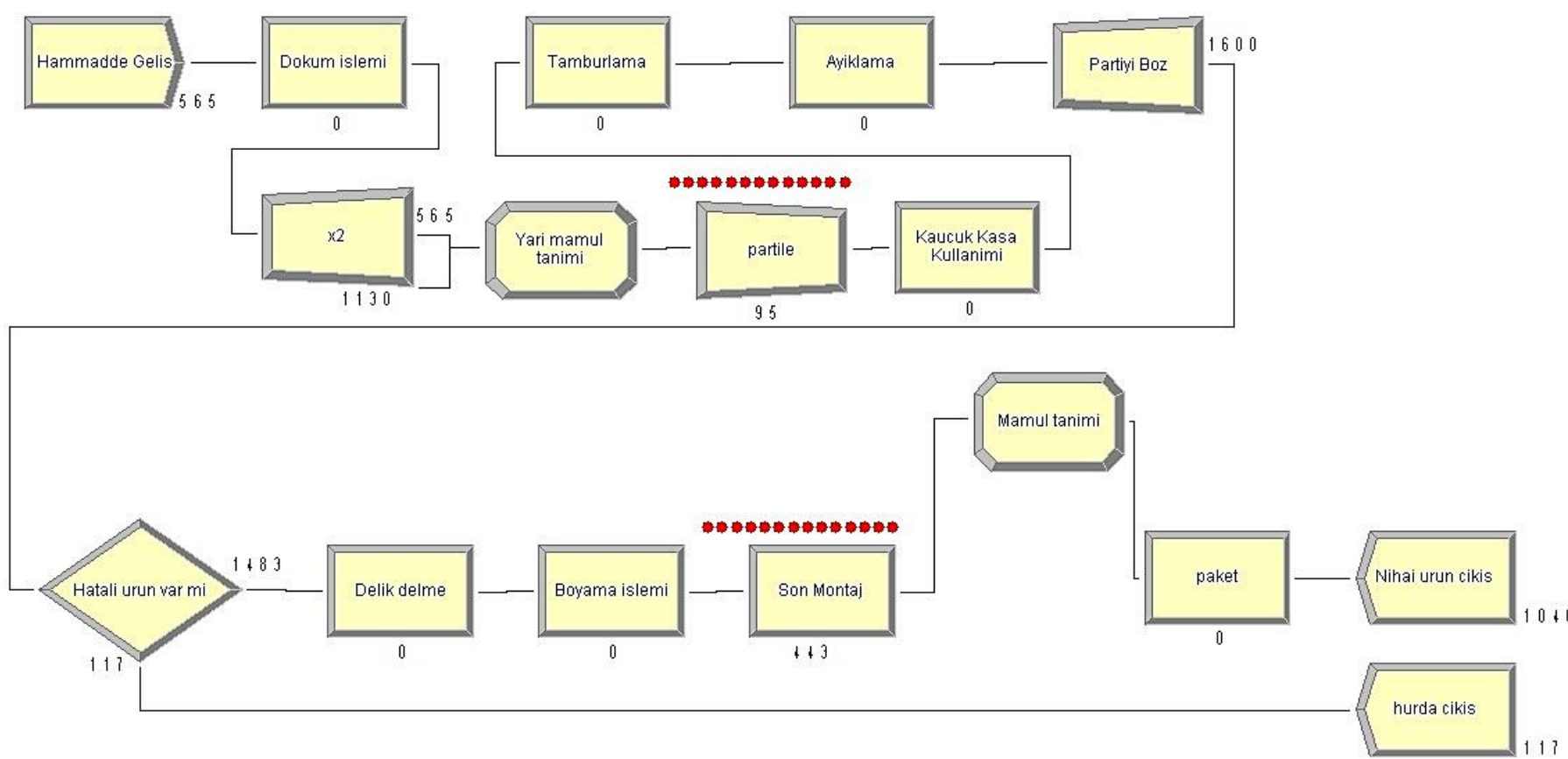

\section{Şekil 5. Benzetim Modeli}

Toplanan veriler doğrultusunda mevcut sistemin animasyon grafiği şekil 5'de verilmiştir. Şekil üzerindeki kırmızı noktalar darboğaz oluşan prosesleri ifade etmektedir. Proseslerin yanında bulunan rakamlar ise $o$ prosese ait süreç içi stokları göstermektedir.

Modelde 7 ana iş istasyonu ve 1 adet "kauçuk kasa kullanımı" yardımeı prosesi bulunmaktadır.

- Hammaddenin sisteme gelişi ile başlayan süreç, döküm işlemi ile devam etmektedir. Döküm işleminde, kaynak olarak enjeksiyon makinesi kullanılmaktadır.

Döküm işleminde kullanılan makine kalıbının tasarımı gereği her bir baskıda 2 adet çıktı elde edilmektedir. Bu nedenle gerçekleşen her bir işlem sonucu parçaların birebir kopyasını sisteme tanıtmak amacıyla "x2" adındaki Separate modülü kullanılmıştır. Aynı zamanda Assign modülü ile de yarı mamül olduğu sisteme tanıtılmıştır.

- Daha sonra Batch modülü ile yarı mamüllerden 200 adetlik partiler oluşturularak, kauçuk kasalar yardımıyla tamburlama makinesine taşınmaktadır. Kaynak olarak eleman görevlendirilmiştir. Partileme miktarı ürün boyutlarına bağlı olarak tambur makinesinin haznesine göre düzenlenmektedir.

- Burada bir süre işlem gören parçalar ayıklanarak hatalı ürün kontrolünden geçirilmektedir. Üretimden elde edilen verilerin analizi sonucu $\% 8$ hatalı yarı mamül ayıklanmakta ve bu yarı mamüller daha sonrasında eritilerek tekrar sisteme girişinin sağlanması için hurda çıkışına gönderilmektedir.

- Delik delme prosesinde kaynak olarak 1 adet masa üstü matkap ve 1 işçi çalışmaktadır.

- Boyahane de boyama işlemi gerçekleşen parçalar üst ve alt gövdelerin montajı için son montaj prosesine gönderilmektedir. Son montaj prosesinde kaynak olarak 1 adet şarjlı el matkabı ve 1 işçi çalışmaktadır.
- Son montaj işleminden çıkan parçalar, Assign modülü ile varlık tipi mamül olarak atanmıştır.

- Son olarak mamüller paketlenerek sevkiyata hazır hale getirilir.

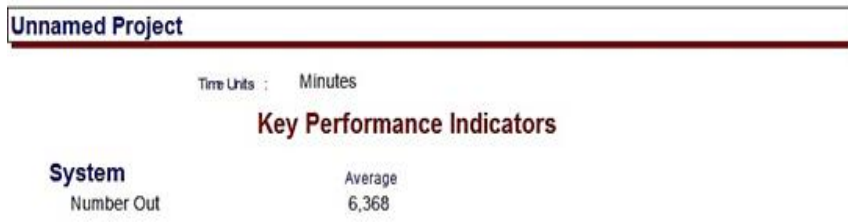

\section{Şekil 6 Toplam çıktı miktarını gösteren rapor}

Tamburlama işleminden sonra yarı mamüllerin \%8 ‘ $\mathrm{i}$ hurdaya ayıklanmaktadır. Hurda olarak sistemden çıkan bu ürünler daha sonra tekrar eritilmek üzere makinenin haznesine atılmaktadır. Her ne kadar ürünlerin hammadde olarak geri dönüşü sağlansa da, üretim de harcanan enerji ve iş gücü dolayısıyla bu hataların azaltılması gerekmektedir. Neden-sonuç (balık kılçı̆̆ı) diyagramı, herhangi bir olası nedeni listelemek için etkili ve basit bir araçtır. Bu nedenle üretim şefi önderliğinde, sistem incelenerek beyin firtınası yapılmış ve hatalara sebep olabilecek alt nedenler balık kılçı̆̆ diyagramı ile belirlenmiştir (Şekil 7).

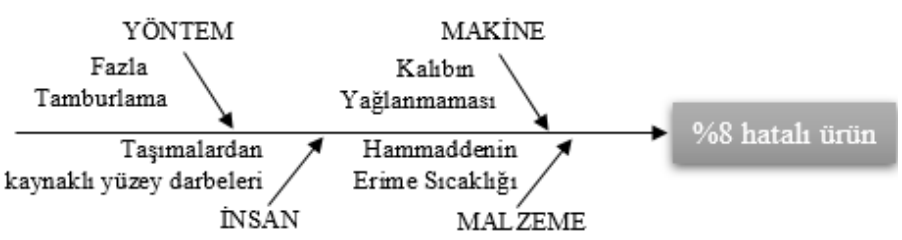

Şekil 7 Hatalı ürün balik kılçığı diyagramı

Sistem "Yöntem" bazında incelendiğinde fazla tamburlama yapılmasının ürünün geometrik yapısına zarar verdiği gözlemlenmiştir. Tamburlama işleminin, standart süresinden 
fazla yapılmasına izin verilmemesi için bu makine için andon sistemler geliştirilebilmesi düşünülmüştür.

Sistem "Makine" bazında incelendiğinde kalıp yüzeyinin yeteri kadar yağlanmaması nedeniyle ürünlerin kalıpdan çıkarken zorlandığı ve bu yüzden hurda çıkışına gönderilebileceği gözlenmiştir. Burada kalıbın yağlanma işleminin daha sıklıkla yapılması önerilmiştir.

Sistem "İnsan" bazında incelendiğinde taşımalardan kaynakl1, ürünler üzerinde darbe ve çiziklerin oluşabildiği gözlemlenmiştir. Bu durumu önlemek amacıyla döküm ve tambur prosesleri arasında kauçuk kasalar kullanılmaktadır. Kauçuk kasaların tüm prosesler arası kullanımının zorunlu hale getirilmesiyle ürünlerin daha korunaklı taşınabileceği ve böylelikle hataların azaltılabileceği düşünülmüştür.

Sistem "Malzeme" bazında incelendiğinde eriyik hammaddenin, yolluk kısmından kalıbın içerisine yüklenmesinde tam dolum gerçekleşmemesi sonucu hatalı çıktılar elde edilebilmektedir. $\mathrm{Bu}$ durumun en büyük nedenlerinden biri hammaddenin erime sıcaklığı noktasına gelmeden döküm işlemi gerçekleştirmeye çalışmaktır. Buna engel olmak için hammaddenin eridiği ocak olan güzinenin sıcaklığını kontrol etmek gerekmektedir.

Sistemde ki darboğazlar incelendiğinde partileme prosesi üzerinde oluşan kuyruk 200 adetlik hacmin dolması için mecburi beklenen sıra, son montaj prosesinde oluşan kuyruk ise çözüm geliştirilmesi gereken darboğaz olarak görülmektedir. Son montaj işleminde görülen kuyruk, kapasite yetersizliği ya da ürün montajında karşılaşılan bir problemden kaynaklı olabilir.

Sistem incelendiğinde ürün montajında herhangi bir problem tespit edilmemiş olup ikinci ihtimal üzerinde durulmuş ve son montaj prosesine ait kapasite iki katına çıkarılmıştır. Şekil 8'de geliştirilmiş sistem çıktı miktarının gösterildiği Arena dan elde edilen rapor verilmiştir.

\begin{tabular}{cc|}
\hline Unnamed Project & \\
\hline & The unts : Minutes \\
& Key Performance Indicators \\
System & Average \\
Number Out & 8,379
\end{tabular}

Şekil 8 İyileştirilmiş sistem çıktı sayısı raporu

Rapora göre yeni durumda çıktı miktarı 8379 adet olmuş ve bir önceki modele göre çıktı sayısında \%31,58 artış sağlanmıştır. Üretim sayısı arttığı için, müşteriye siparişleri zamanında teslim etmek kolaylaşmıştır. Şekil 9'de mevcut model ile geliştirilmiş modele ait çıktı miktarları verilmiştir.

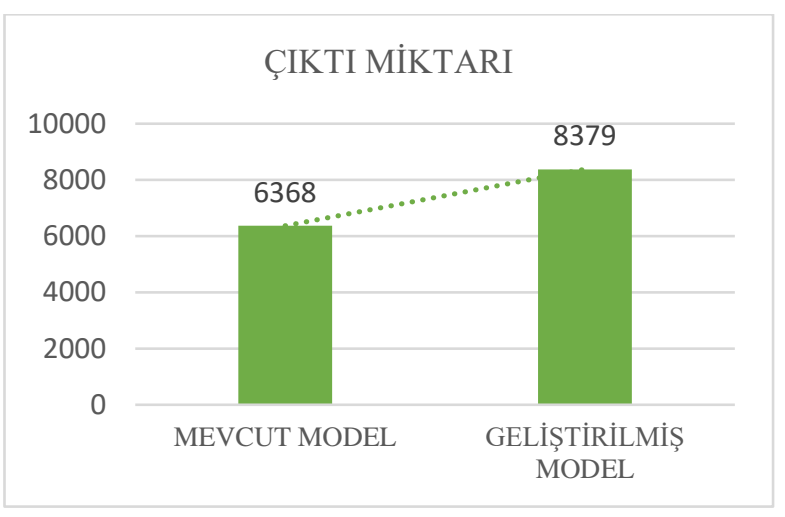

Şekil 9 Mevcut model-geliştirilmiş model çıktı miktarları e-ISSN: 2148-2683
Bununla birlikte yeni işçi alımı ve yeni kaynak alımına ait yatırım maliyetleri aşağıdaki şekilde hesaplanmıştır;

$$
\text { Aylık mesai ücreti }=3.250,0 \mathrm{tl}
$$$$
\text { İşe alım maliyeti }=4.000,0 \mathrm{tl}
$$$$
\text { Şarjlı matkap maliyeti }=2.800,0 \mathrm{tl}
$$

Firmanın gizlilik hakları gereği ürün maliyetine bu kısımda yer verilmemiş ortalama bir maliyet gösterilmiştir. Emniyet kilidi ürününe ait ;

Aylık ortalama satış geliri $=25.200,0 \mathrm{tl}$

Sabit Giderler (elektrik, kira,vb.) =11.000,0 tl

Değișken Giderler (hammadde fiyatı, ișçilik, vb.)

$$
=5.000,0 \mathrm{tl}
$$

Buradan,

$$
\text { Aylık kazanç }=25.200,0-11.000,0-5.000,0=
$$
9.200,0 tl olur.

Kapasite arttırımı ile katlanılacak maliyetler toplamı $3.250,0+4.000,0+2.800,0=10.050,0 \mathrm{tl}$ olmuş ve firma, sisteme kazandırılan ürünlerden elde edilecek gelir ile yatırımını 1 ayda amorti ederek daha hızlı çalışma kapasitesi yakalayabilecektir.

\section{Sonuç}

Bu çalışmada, pimapen kapı ve pencere sistemlerine üretim yapan bir işletmenin hırsız emniyet kilidi üretim hattındaki gecikmeleri ve beklemeleri tespit edip, gidermek amaçlı bir modelleme çalışması yapılmıştır. İlk olarak sistem analizi yapılmış, proseslerin süreleri uzman görüşleri alınarak incelenmiş ve değer yaratmayan işlere neden olabilecek aksiyonlar incelenmiştir. Daha sonra mevcut sistem Arena 14.0 yazılımında modellenmiştir.

Modelin çalıştırılması sonucu 6368 adet çıktı elde edilmiştir. $\mathrm{Bu}$ ürünlerin $\% 8 \mathrm{i}$ geri dönüştürülmek üzere sistemden çıkmaktadır. $\mathrm{Bu}$ ürünlerin üretim akışında hatalı ürün olarak ayrıştırılmasına neden olabilecek alt nedenler balık kılçığı diyagramı kullanılarak tespit edilip, üzerine tartışılarak bu hataları engellemek amaçlı bazı aksiyonlar belirlenmiştir.

Son montaj prosesinde oluşan uzun kuyrukları ortadan kaldırmak amaçlı kapasite arttırımı yapılarak çıktı sayısında \%31,58 artış sağlanmıştır. Yatırım yapmadan önce yatırım maliyeti, üretim miktarı oranı ve yapılacak yatırım sonucu karın artıp artmayacağının hesaplanması gerekmektedir. Burada bir kez daha simülasyon yönteminin önemi vurgulanmak istenmiştir. Yapılan yatırım maliyetinin kısa bir sürede amorte edilebilceği hesaplanmıştır.

Çalışmanın sonucunda geliştirilen model ile elde edilen çıktı sayısındaki artışın firmanın sektörde rekabet gücünü arttırması ve sipariş teslim sürelerini kısaltarak diğer ürün üretimleri için de işletmeye kazanç sağlaması beklenmektedir.

\section{Teşekkür}

Bu çalışmanın yürütülmesi sırasında desteğini esirgemeyen işletme üretim şefine ve uygulamanın yapıldığ 1 işletme sahibine ve çalışmam sırasında yardımlarını esirgemeyen herkese teşekkür ederiz. 


\section{Kaynakça}

[1] Popovics, G., Pfeiffer, A., Monostori, L., Generic data structure and validation methodology for simulation of manufacturing systems, International Journal of Computer Integrated Manufacturing, Issue 12: Economic Development And Wealth Through Globally, Volume 29, Page:1272-1286, 2016.

[2] Ünal, C., Bilget, S., Examination of lean manufacturing systems by simulation technique in apparel industry, The Journal of The Textile Institue, 2020.

[3] Neeraj, R., R., Nithin, R., Niranjhan, P., Sumesh, A., Thenarasu, M., Modelling And Simulation of Discrete Manufacturing Industry, Materialstoday: Proceedings, Volume 5, Issue 11, Part 3, Pages : 24971 - 24983, 2018

[4] Kocaköz, Y., LPG Silindir İmalat Hattının Simülasyon İle Yeniden Düzenlenmesi, Maltepe Üniversitesi, Fen Bilimleri Enstitüsü, Yüksek Lisans Tezi, 2019.

[5] Arslankaya, S., Duran, E., Jeneratör Üreten Bir Firmada Kabin Kaynak Hattının Simülasyon İle İyileştirme
Çalışması, Sakarya Üniversitesi, SETSCI Conference Proceedings 4 (6), S. 61-72, 2019.

[6] Sütçü, A., Karşıyaka, O., Burhan, M., E., Bir Mobilya Üretim Tesisisnde İş Analizi ve Benzetim Uygulaması İle Süreç Verimliliğinin Artırılması, Araştırma Makalesi, Avrupa Bilim ve Teknoloji Dergisi, Sayı 17, S. 45-47, Aralık 2019 [Google Akademik]

[7] Sakcalı, A., Burhan, M., E., Saraç, M., S., Bir Mermer Ocağında Simülasyon Destekli Performans Analizi, Proceedings of 6th International Congress of Mining Machinery \& Technologies, 2017

[8] Yelkenci, S., Tunalı, S., Eşanjör Üretim Hattında Simülasyon Kullanılarak Darboğaz İstasyonların Belirlenmesi, Atatürk Ü. İİBF Dergisi, 10. Ekonometri ve İstatistik Sempozyumu Özel Sayıs1, 2011

[9] Krishnan, S., Dev, S., Suresh, R., Sumesh, A., Rameshkumar, K., Bottleneck İdentification İn A Tyre Manufacturing Plant Using Simulation Analysis And Productivity Improvement, 2018

[10] Goldsman D., Introduction to simulation. Proceedings of the 2007 Winter Simulation Conference, 26-37, 2007 